\title{
Solubility and Dissolution Enhancement of Ebastine by Surface Solid Dispersion Technique
}

Lina S. Hussein ${ }^{* 1}$ and Eman B. H. Al-Khedairy ${ }^{* *}$

*Department of Clinical and Laboratory Sciences, College of Pharmacy, Thi-Qar University, Thi-Qar, Iraq **Department of Pharmaceutics College of Pharmacy, University of Baghdad, Baghdad, Iraq.

\section{Abstract}

Ebastine (EBS) is a non-sedating antihistamine with a long duration of action. This drug has predominantly hydrophobic property causing a low solubility and low bioavailability. Surface solid dispersions (SSD) is an effective technique for improving the solubility and dissolution rate of poorly soluble drugs by using hydrophilic-water insoluble carriers.

The present study aims to enhance the solubility and dissolution rate of EBS by using SSD technique. Avicel® PH101, Avicel® PH 102, croscarmellose sodium(CCS) and sodium starch glycolate (SSG) were used as water insoluble hydrophilic carriers.

The SSD formulations of EBS were prepared by the solvent evaporation method in different drug: carrier weight ratios, then evaluated for their percentage yield, drug content, water solubility, release in $0.1 \mathrm{~N} \mathrm{HCl}$, Powder X-Ray Diffraction (PXRD) in addition to Fourier Transform Infrared Spectroscopy (FTIR) for the determination the drug-carrier interaction.

Most of the prepared SSD formulas showed improvement of drug solubility. The best result was obtained with formula SSD16 (EBS: CCS 1:15) that showed high percentage yield (98.5\%), high drug content (98.39\%) and 8.2 fold increase in solubility compared to solubility of pure drug with improved dissolution rate. The drug was converted to amorphous form without chemical interaction with the carrier. So, it can be concluded that the solubility and the dissolution rate of EBS were successfully enhanced by SSD technique prepared by solvent evaporation method using hydrophilic-water insoluble carriers.

Keywords: Ebastine, Surface solid dispersion, Solvent evaporation technique.

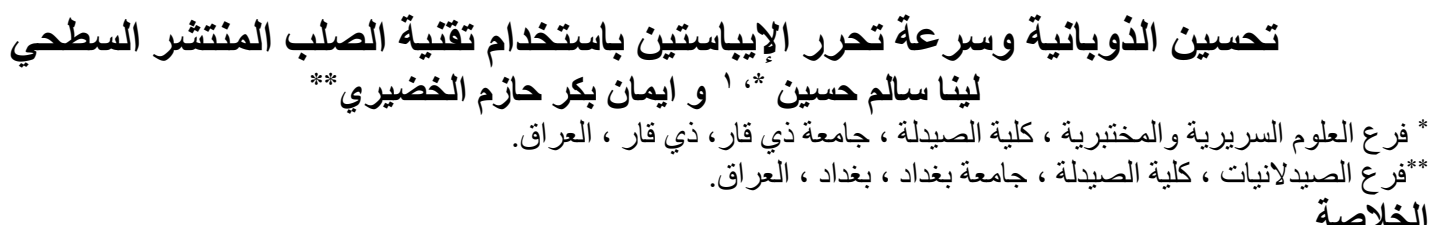

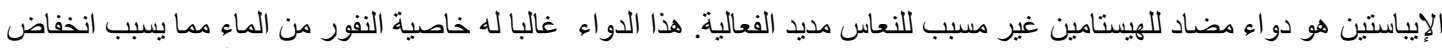

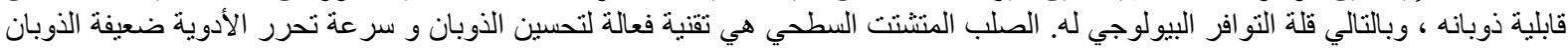

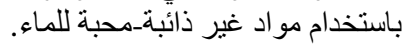

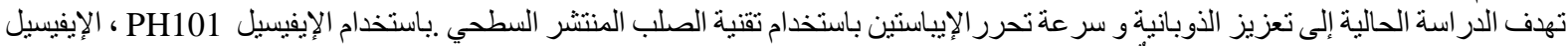

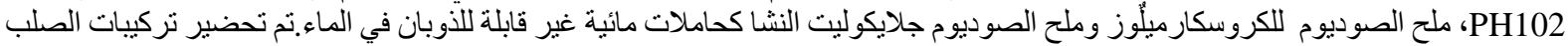

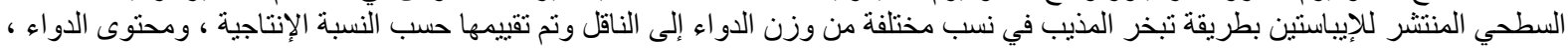

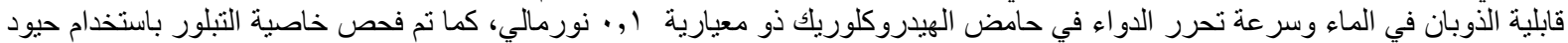

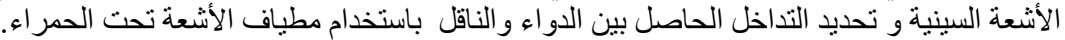

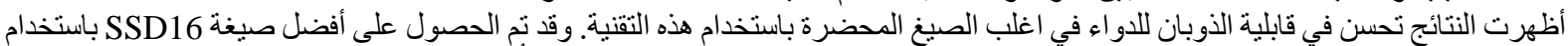

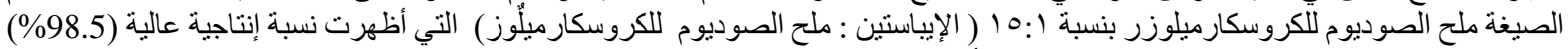

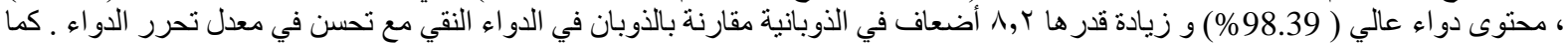

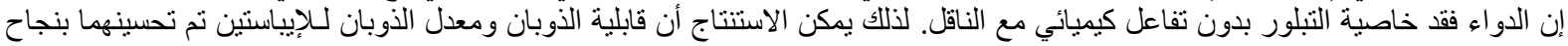

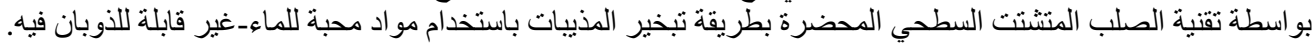

\section{Introduction}

Solubility is a property of substance in a particular solvent. In quantitative terms, it is a concentration of dissolved solute in a saturated solution at a certain temperature. In qualitative terms, it means spontaneous interaction of two or more substances to form one phase, clear homogeneous molecular dispersion. Dissolution is
الكلمات المفتاحية :دواء الإيباستين، الصلب المنتشر السطحي، تقنية التبخر بالمذيبات

the process by which the solute dissociates in a solvent forming a molecular level, physically and chemically homogenous dispersion called a solution. Solubility and dissolution are dissimilar concepts but are connected.Most of the new drugs have poor aqueous solubility; thereby have a difficulty in formulating in drug delivery systems.

${ }^{1}$ Corresponding author E-mail: ph.lina.salm@gmail.com

Received: $14 / 8 / 2020$

Accepted:14/10/2020

Iraqi Journal of Pharmaceutical Science 
Therefore, the enhancement of solubility and dissolution rate of these drugs are important preformulation steps in the pharmaceutical product development research. In general, solubility difficulties are faced in the class II and class IV of the Biopharmaceutical Classification System (BCS) where dissolution becomes the rate limiting step for the drug absorption ${ }^{(1-3)}$.

Many techniques have been applied for improving the solubility of poorly soluble drugs such as salt formation, converting into prodrugs, micronization and nanonization, complexation, micelles, emulsions, solid-lipid nanoparticles, and solid dispersions. Among these, solid dispersion (SD) is gaining tremendous significance to enhance solubility and dissolution of poorly soluble drugs. It can be defined as molecular mixture of poorly soluble drugs in hydrophilic carriers. These carriers play an important role in drug release according to their properties ${ }^{(4)}$.

Surface solid dispersion (SSD) is another technique for dispersing one or more active ingredients on a water insoluble-hydrophilic carrier of extremely high surface area to achieve increased dissolution rates and bioavailability of insoluble drugs. When in contact with water, this carrier disperses immediately allowing the fast release of the drug. SSD can overcome some of the disadvantages of the conventional SDs which prepared by water soluble carriers like tackiness and difficulty in handling of the product. Many commonly used excipients like microcrystalline cellulose, silicon dioxide, sodium starch glycolate, potato starch and croscarmellose, have been used as carriers for preparing $\operatorname{SSD}^{(5,6)}$.

Ebastine (EBS) a piperidine derivative, is a nonsedating antihistamine with a long duration of action. Chemical structure of EBS is shown in figure 1. It is a basic compound that contains tertiary amine group with pKa 8.8 and partition coefficient of 7.64. This drug belongs to BCS class II, thus when

Table 1. Composition of different EBS SSD formulas . administered orally, it is not readily bioavailable ${ }^{(7,}$ 8).

The objective of this research was enhancing the solubility and dissolution rate of EBS by SSD technique, using different hydrophilic-water insoluble carriers at different ratios.

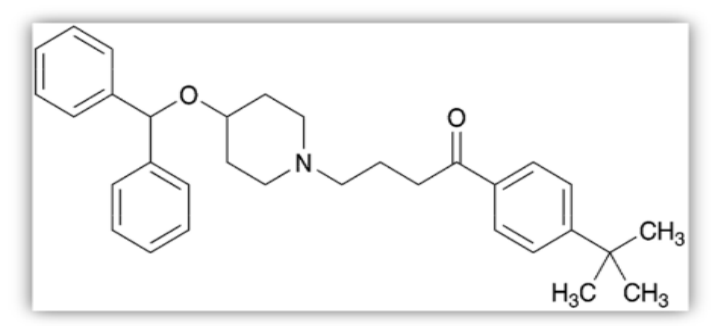

Figure 1. Chemical structure of Ebastine ${ }^{(9)}$

\section{Materials and Methods Materials}

Ebastine and Croscarmellose sodium were purchased from Hangzhou, Hyperchem- China. Avicel ${ }^{\circledR}$ PH101, Avicel ${ }^{\circledR}$ PH 102 and Sodium starch glycolate (SSG) were gifted from Pioneer pharmaceutical company, Iraq.

\section{Methods}

Preparation of surface solid dispersion (SSD) of EBS

Ebastine SSDs were prepared by solvent evaporation method using different hydrophilic carriers. Specified amount of the drug was dissolved in methanol to obtain a clear solution. Then after, an accurate amount of carrier corresponding to different drug: carrier w: $w$ ratios were added to the drug solution (Table 1). The formed suspension was continuously stirred using magnetic stirrer at room temperature till all the methanol evaporated. The dried SSD mass was pulverized and passed through sieve no. 230. Then they were stored in a desiccator containing anhydrous calcium chloride as a drying agent. This agent was used to reduce the humidity in a desiccator producing a dry environment (at least $24 \mathrm{~h}$ ) for analysis ${ }^{(10)}$.

\begin{tabular}{|c|c|c|c|c|c|c|}
\hline $\begin{array}{l}\text { Formula } \\
\text { Number }\end{array}$ & $\begin{array}{l}\text { EBS:Carrier } \\
\text { w:w ratio }\end{array}$ & $\begin{array}{l}\text { Ebastine } \\
\text { (g) }\end{array}$ & $\begin{array}{l}\begin{array}{l}\text { Avicel@ PH } 101 \\
\text { (g) }\end{array} \\
\end{array}$ & $\begin{array}{l}\text { Avicel } \AA \text { PH } 102 \\
\text { (g) }\end{array}$ & $\begin{array}{l}\mathrm{CCS} \\
(\mathrm{g})\end{array}$ & $\begin{array}{l}\text { SSG } \\
(\mathrm{g})\end{array}$ \\
\hline EBS1 & \multirow{4}{*}{$1: 1$} & 0.5 & 0.5 & - & - & - \\
\hline EBS2 & & 0.5 & - & 0.5 & - & - \\
\hline EBS3 & & 0.5 & - & - & 0.5 & - \\
\hline EBS4 & & 0.5 & - & - & - & 0.5 \\
\hline EBS5 & \multirow{4}{*}{$1: 2$} & 0.5 & 1 & - & - & - \\
\hline EBS6 & & 0.5 & - & 1 & - & - \\
\hline EBS7 & & 0.5 & - & - & 1 & - \\
\hline EBS8 & & 0.5 & - & - & - & 1 \\
\hline EBS9 & \multirow{4}{*}{$1: 5$} & 0.5 & 2.5 & - & - & - \\
\hline EBS10 & & 0.5 & - & 2.5 & - & - \\
\hline EBS11 & & 0.5 & - & - & 2.5 & - \\
\hline EBS12 & & 0.5 & - & - & - & 2.5 \\
\hline EBS13 & \multirow[b]{2}{*}{$1: 10$} & 0.5 & 5 & - & - & - \\
\hline EBS14 & & 0.5 & - & - & 5 & - \\
\hline EBS15 & \multirow[b]{2}{*}{$1: 15$} & 0.5 & 7.5 & - & - & - \\
\hline EBS16 & & 0.5 & - & - & 7.5 & - \\
\hline
\end{tabular}




\section{Preparation of physical mixture (PM)}

Physical mixture was prepared for the selected SSD formula by mixing the powders geometrically in a glass mortar using spatula which was then passed through sieve no.230 then stored in the desiccator for further use ${ }^{(11)}$.

\section{Evaluation of SSD of Ebastine}

Determination of percentage yield

The percent of yield of SSDs was calculated by using the following Equation ${ }^{(12)}$ :

$$
\% \text { of yield }=\frac{\text { Weight of SSDs }}{\text { Weight of drug }+ \text { weight of carrier }} \times 100
$$

\section{Determination of drug content of SSD}

Monitoring drug content uniformity is required for the control of drug quality and durability of the process. A precisely weighed quantity of SSD powder equivalent to $15 \mathrm{mg}$ of EBS was weighed accurately and dissolved in $30 \mathrm{ml}$ of methanol. The resulted mixture was filtered through a $0.45 \mu \mathrm{m}$ membrane filter then suitably diluted with methanol. The absorbance of the solution was measured at $253 \mathrm{~nm}{ }^{(13)}$. Experiments were repeated three times. The percentage of drug content in the SSD was counted by the following equation ${ }^{(14)}$ :

Drug content $=\frac{\text { Practical drug content }}{\text { Theoretical drug content }} \times 100$

\section{Determination of saturation solubility of SSD}

An excess amount of EBS and the prepared SSDs was added to $10 \mathrm{ml}$ of distilled water in plain tubes. The test tubes were tightly closed and continuously stirred on isothermal water bath shaker for $48 \mathrm{~h}$ at $25^{\circ} \mathrm{C}$ to get equilibrium. Then, a millipore filter syringe of $0.45 \mu \mathrm{m}$ was used for filtering the samples. The dissolved amount was determined by UV spectrophotometer at $256 \mathrm{~nm}^{(15)}$. This study was done in triplicate.

\section{Determination of hydration capacity}

According to the solubility study, one gram of the best carriers' formulas was placed separately in $10 \mathrm{ml}$ pre-weighed centrifuge tube. Sufficient distilled water was added to make up the volume to $10 \mathrm{ml}$ and the suspension was shaken manually for $5 \mathrm{~min}$. The suspension was allowed to stand for 10 min and then by centrifugation for $15 \mathrm{~min}$ at 1000 rpm. Then after, the supernatant was decanted. Then a tube was reweighed, and hydration capacity was calculated by using the following equation ${ }^{(16)}$ :

Hydration capacity $\%=$

Weight of tube with sediment -weight of empty tube $\times 100$

\section{Comparative in-vitro dissolution studies of pure and SSDs of EBS}

The accurately weighed samples equivalent to $10 \mathrm{mg}$ of EBS were placed in USP type II dissolution apparatus. In-vitro dissolution study was done for pure drug, selected SSD formula and PM. This test was performed using $1000 \mathrm{ml} 0.1 \mathrm{~N}$ $\mathrm{HCl}$ with $100 \mathrm{rpm}$ paddle speed at $37 \pm 0.5^{\circ} \mathrm{C} .5 \mathrm{ml}$ of sample was taken at certain time intervals 10,15 ,
20, 30, 40, 50 and 60 min. and substituted with an equal volume of fresh dissolution medium. After filtering, the samples were analyzed spectrophotometrically at $257 \mathrm{~nm}$. The drug dissolution profile was plotted as percentage of drug release versus time ${ }^{(17)}$.

\section{Fourier transform infrared (FTIR) analysis}

The FTIR spectra of pure drug, the best carrier, physical mixture PM and the selected SSD formulation were recorded by using FTIR (IRAffinity-1) spectrophotometer (Shimadzu, Japan). The samples were scanned over 4000-400 $\mathrm{cm}^{-1}$ frequency range ${ }^{(18)}$.

\section{Powder X-ray diffraction (PXRD) analysis}

The PXRD was used to detect any changes in the drug crystalline nature and to determine the possibility of any polymorphic changes of drug in the SSD formulation that may influence its dissolution. The X-ray diffractograms of the drug, the best carrier, PM and optimized SSD formulation were obtained by using X-ray diffractometer (Shimadzu, Japan) ${ }^{(19)}$. The scanning speed was $5^{\circ} / \mathrm{min}$ over a $2 \theta$ range of $5-80^{\circ}$.

\section{Statistical analysis}

The dissolution profiles were statistically checked using a similarity factor $(f 2)$. This factor have a value range between 0 and 100. The two dissolution profiles consider the same when $f 2$ values more than $50(50-100)$; while $f 2$ values less than 50 indicates that the compared profiles are not the same. The similarity factor $(f 2)$ was defined by the following equation ${ }^{(20)}$.

$$
\mathrm{f}_{2}=50 \times \log \left\{\left[1+\frac{1}{n} \sum_{t=1}^{n}\left|R_{t}-T_{t}\right|^{2}\right]^{-0.5} \times 100\right\}
$$

Where (n) is the number of dissolution time points. (Rt),(Tt) is the reference and test dissolution values as $\%$ at time $(\mathrm{t})$, respectively.

The other results were analyzed using Paired samples T Test (SPSS) and the level of significance was set at a p-value of 0.05 :

A $p$ value $>0.05$ was considered to be nonsignificant.

A $p$ value $<0.05$ was considered to be significant

\section{Results and Discussion Percentage yield}

High percentage yield was obtained from all the SSDs formulas that range between $96-99 \%$ as shown in table 2 . This indicates that there was no more than $4 \%$ loss in SSD obtained products which shows the suitability of the solvent evaporation method in the preparation of EBS SSDs.

\section{Drug content of SSDs}

All tested formulations of SSDs showed acceptable drug content ranging from $97-99 \%$ w/w as observed in table 2 which was in agreement with USP requirements $(90-110 \%){ }^{(21)}$. These results indicated a homogeneous distribution of the prepared formulations. 
Table 2. Percentage yield and drug content of prepared SSDs

\begin{tabular}{|c|c|c|c|}
\hline Formula Number & $\begin{array}{l}\text { Formula composition } \\
\text { (Drug: Carrier w:w ratio) }\end{array}$ & $\begin{array}{l}\text { Percentage yield } \\
(\text { PY \%) }\end{array}$ & $\begin{array}{l}\text { Drug content } \\
(w / w)(\%) \\
(\text { Mean } \pm S D), n=3\end{array}$ \\
\hline SSD1 & (1:1EBS:Avicel@PH101) & 96.2 & $98.67 \pm 1.95$ \\
\hline SSD2 & (1:1EBS:Avicel@PH102) & 96 & $99.68 \pm 4.15$ \\
\hline SSD3 & $(1: 1 E B S: C C S)$ & 99.9 & $99.82 \pm 2.40$ \\
\hline SSD4 & $(1: 1 E B S: S S G)$ & 99.3 & $98.39 \pm 5.87$ \\
\hline SSD5 & (1:2EBS:Avicel@PH101) & 98.4 & $98.38 \pm 1.39$ \\
\hline SSD6 & (1:2EBS:Avicel@PH102) & 95.5 & $99.80 \pm 3.44$ \\
\hline SSD7 & (1:2EBS:CCS) & 98.7 & $98.24 \pm 3.25$ \\
\hline SSD8 & $(1: 2 \mathrm{EBS}: \mathrm{SSG})$ & 97 & $98.68 \pm 1.52$ \\
\hline SSD9 & (1:5EBS:Avicel@PH101) & 98.4 & $98.67 \pm 1.64$ \\
\hline SSD10 & (1:5EBS:Avicel@PH102) & 97.5 & $98.96 \pm 3.37$ \\
\hline SSD11 & (1:5EBS:CCS) & 99.2 & $97.23 \pm 1.14$ \\
\hline SSD12 & (1:5EBS:SSG) & 98.8 & $99.82 \pm 0.44$ \\
\hline SSD13 & (1:10EBS:Avicel@PH101) & 98.2 & $99.69 \pm 4.24$ \\
\hline SSD14 & $(1: 10 \mathrm{EBS}: \mathrm{CCS})$ & 99.4 & $98.24 \pm 4.24$ \\
\hline SSD15 & (1:15EBS:Avicel@PH101) & 96.9 & $99.68 \pm 3.07$ \\
\hline SSD16 & $(1: 15 E B S: C C S)$ & 98.5 & $98.39 \pm 6.64$ \\
\hline
\end{tabular}

\section{Saturation solubility of EBS SSDs}

Most of the prepared SSDs of EBS showed a significant improvement in their water saturated solubility compared to that of pure drug as shown in table 3 . This could be due to the hydrophilic nature of these carriers and surface adsorption of drug particles on these carriers in an extremely fine state of subdivision or molecular form. The resulting decrease in particle size and the increase in the interfacial area of contact between the drug particles and the solvent increased the solubility of the drug compared to the drug alone. In addition, the affinity between the hydrophilic inert carriers and the solvent facilitated the penetration of the solvent into the particles that resulted in further enhancement of the solubility of drug ${ }^{(22-24)}$.

This enhancement was affected by the type of the carrier and drug: carrier ratio. Table 3 showed that, no improvement in the solubility of EBS was obtained by using 1:1 drug: carrier w:w ratio, but significant enhancement in drug solubility $(\mathrm{p}<0.05)$ at 1:2 ratio in the following sequence:

CCS (SSD7) > Avicel $®$ PH101 (SSD5) > SSG (SSD8) > Avicel@ PH102 (SSD6)

Also, it was found that the saturated solubility of EBS increased significantly $(p<0.05)$ with an increase in drug: carrier ratio from $1: 2$ to $1: 5$ for all the used carriers with exception of SSG. A higher amount of the carrier resulted a larger amount of EBS dispersed over the carrier surface and hence improved EBS wettability and solubility ${ }^{(25)}$.

Among carriers were CCS and Avicel® ${ }^{\circledR}$ PH101 exhibited highest improvement of solubility at 1:5 drug: carrier ratio in comparison with the others, since they produced 3.5, 2.9 folds increase in solubility, respectively.
The small particle size of CCS $(\sim 50 \mu \mathrm{m})$, Avicel ${ }^{\circledR}$ PH101 $(\sim 50 \mu \mathrm{m})$ compared to Avicel ${ }^{\circledR P H} 102$ (100 $\mu \mathrm{m})$ resulted in a larger surface available for adsorption of the EBS particles which would provide better drug wetting ability associated within them ${ }^{(10,26,27)}$

On the other hand, SSG with very small particle size (38 $\mu \mathrm{m})$, although it increased the saturated solubility compared to the pure drug, but there was no significant $(p>0.05)$ improvement in the saturated solubility by increasing the proportion of this carrier from 1:2 (SSD8) to 1:5 (SSD12). This was due to enough surface area of SSG for all drug particles at ratio 1:2 w:w drug: SSG so that, further increase in SSG at 1:5 ratio was of no benefit because all drug particles adsorbed and no more was available for extra adsorption ${ }^{(10,28)}$.

Therefore, CCS and Avicel ${ }^{\circledR}$ PH101 were chosen preferably for SSDs preparation to proceed with this study. The results of the solubility study showed that an increase in the CCS ratio (1:10 and 1:15) lead to EBS solubility improvement (6.3folds and 8.2folds, respectively as compared with the solubility of pure EBS). While the results of Avicel® PH101 showed the higher improvement of drug solubility occur with 1:10 ratio SSD13 (3.4 folds) in comparison to 1:15 ratios SSD15 (3 folds). These results might be due to the differences in their hydration capacity. 
Table 3. The saturated solubility of EBS SSDs prepared with several Drug:Carrier w:w ratios in distilled water at $25^{\circ} \mathrm{C}$.

\begin{tabular}{|c|c|c|}
\hline Formula Number & $\begin{array}{l}\text { Formula Composition } \\
\text { (Drug: Carrier w:w ratio) }\end{array}$ & $\begin{array}{l}\text { Saturation solubility } \\
\text { mg/ml } \\
(\text { Mean } \pm \text { SD }), n=3\end{array}$ \\
\hline \multicolumn{2}{|l|}{ Pure EBS } & $0.0017 \pm 0.0004$ \\
\hline SSD1 & (1:1EBS:Avicel@PH101) & $0.0017 \pm 0.0008$ \\
\hline SSD2 & (1:1EBS:Avicel®PH102) & $0.0018 \pm 0.0009$ \\
\hline SSD3 & $(1: 1 \mathrm{EBS}: \mathrm{CCS})$ & $0.0018 \pm 0.0001$ \\
\hline SSD4 & (1:1EBS:SSG) & $0.0020 \pm 0.0001$ \\
\hline SSD5 & (1:2EBS:Avicel@PH101) & $0.0031 \pm 0.0001$ \\
\hline SSD6 & (1:2EBS:Avicel®PH102) & $0.0022 \pm 0.0004$ \\
\hline SSD7 & (1:2EBS:CCS) & $0.0036 \pm 0.0003$ \\
\hline SSD8 & (1:2EBS:SSG) & $0.0023 \pm 0.0001$ \\
\hline SSD9 & (1:5EBS:Avicel@PH101) & $0.0050 \pm 0.0001$ \\
\hline SSD10 & (1:5EBS:Avicel®PH102) & $0.0026 \pm 0.0002$ \\
\hline SSD11 & (1:5EBS:CCS) & $0.0060 \pm 0.0001$ \\
\hline SSD12 & (1:5EBS:SSG) & $0.0021 \pm 0.0002$ \\
\hline SSD13 & (1:10EBS:Avicel®PH101) & $0.0058 \pm 0.0003$ \\
\hline SSD14 & (1:10EBS:CCS) & $0.0107 \pm 0.0006$ \\
\hline SSD15 & (1:15EBS:Avicel®PH101) & $0.0051 \pm 0.0001$ \\
\hline SSD16 & (1:15EBS:CCS) & $0.0140 \pm 0.0001$ \\
\hline
\end{tabular}

\section{Hydration capacity}

Hydration capacity test is an indicator of swelling power or for extent of solid- liquid interaction. The carriers under this test were wetted by water and then evaluated for their water holding capacity. The capacity of CCS was found to be $73.92 \%$ which was superior to Avicel ${ }^{\circledR}$ PH101 (34.95\%). This result confirmed the previous results about the superiority of CCS over Avicel® PH101 in enhancing the solubility of drug as it absorbed more water so it exhibited more wetting effect ${ }^{(29)}$.

Comparative in-vitro dissolution studies

The formulas SSD14 (1:10) and SSD16 (1:15) Drug: CCS ratio were used to study the effect of CCS ratio on in-vitro dissolution profile of EBS, since the highest solubility was obtained by them. Figure 2 demonstrated that both formulas improved dissolution rate in $0.1 \mathrm{~N} \mathrm{HCl}$ in comparison to the pure drug. The dissolution profiles for both ratios (1:10 and 1:15 drug: carrier) were almost similar $(f 2=77.21)$ so that, no further enhancement in dissolution was obtained with an increased in carrier ratio. The dissolution enhancement effect might belong to high swelling, wicking and hydration capacities of the CCS particles that would prevent aggregation of the drug particles and facilitated dissolution ${ }^{(30)}$. It was observed that drug: CCS ratio of 1:10 was sufficient to adsorb the drug and improve the dissolution process as that for $1: 15$ ratio (31).

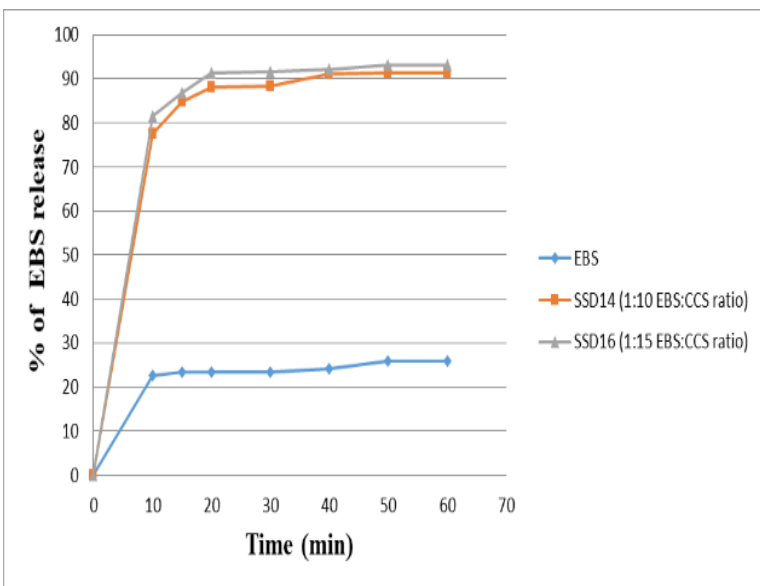

Figure 2. Effect of carrier ratio of SSD on the invitro dissolution of $\mathrm{EBS}$ in $0.1 \mathrm{~N} \mathrm{HCl}$ at $37 \pm 0.5^{\circ} \mathrm{C}$.

Although both SSD14 and SSD16 highly improved the dissolution of EBS, but SSD16 produced more enhancement in solubility than SSD14 (8.2 folds versus 6.3 folds). So that, SSD16 (EBS:CCS 1:15) was selected to be the optimized SSD on the basis of highest drug solubility and improved dissolution of drug.

As well as, the efficiency of SSD technique was demonstrated by comparing the dissolution profile of SSD16 with that of PM and of pure EBS as shown in figure 3. The profile showed that the dissolution rate of EBS in PM as well as in SSD was higher as compared to that of pure EBS. The similarity factor $f 2$ was found to be equal to 9.02 and 40.56 in comparison of SSD16 formula and its PM to pure drug sequentially.

The dissolution of pure EBS was found to be $25.81 \%$ within 60 min whereas, $44.17 \%$ of EBS was released 
after $60 \mathrm{~min}$ from the PM. This might be due to the hydrophilicity of CCS in the respective mixture which rendered this mixture hydrophilic and enhanced the wettability and solubility of drug as indicated from its saturated solubility which was found to be higher than pure drug $(0.0103 \pm 0.0001$ $\mathrm{mg} / \mathrm{ml}$ versus $0.0017 \pm 0.0004 \mathrm{mg} / \mathrm{ml}$ ), yet it was significantly $(\mathrm{p}<0.05)$ lower than its corresponding

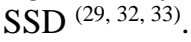

On the other hand, the \% release of EBS from the SSD16 was increased to $93.19 \%$ within $60 \mathrm{~min}$. So that, SSD was an efficient technique to improve the dissolution rate of EBS which might be attributed to a reduction of its particle size and its deposition on the surface of a hydrophilic carrier ${ }^{(34)}$.

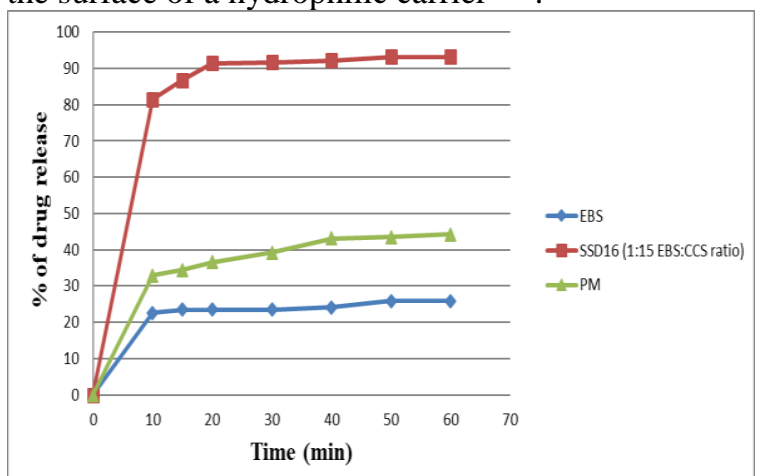

Figure 3. Comparative in-vitro dissolution profile of the pure EBS, SSD16 and physical mixture of $\mathrm{SSD16}(\mathrm{PM})$ in $0.1 \mathrm{~N} \mathrm{HCl}$ at $37 \pm 0.5{ }^{\circ} \mathrm{C}$.
Fourier Transforms Infrared Spectroscopy (FTIR)

The FTIR spectrum of pure EBS and CCS are shown in figures (4) and (5), respectively. The FTIR spectrum of EBS exhibited characteristic bands at $3051 \mathrm{~cm}^{-1}$ for $\mathrm{C}-\mathrm{H}$ stretching of the ring,

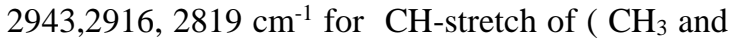
$\mathrm{CH}_{2}$ ), also strong and sharp band at $1678 \mathrm{~cm}^{-1}$ for ketonic carbonyl group ( $\mathrm{C}=\mathrm{O}$ stretch), $1454 \mathrm{~cm}^{-1}$ for aromatic $\mathrm{C}=\mathrm{C}$ stretch of phenyl ring, and $\mathrm{C}-\mathrm{N}$ stretching at $1269 \mathrm{~cm}^{-1}$. These results were in agreement with the previous studies ${ }^{(35-37)}$.

The FTIR spectrum of CCS exhibited characteristic bands at 3360 and $3240 \mathrm{~cm}^{-1}$ for alcoholic O-H groups, $2904 \mathrm{~cm}^{-1}$ for aliphatic C-H stretching of $\left(\mathrm{CH}_{2}\right)$, and weak band at $1732,1720 \mathrm{~cm}^{-1}$ for $\mathrm{C}=\mathrm{O}$ of carboxylic groups. These results were in consistent with the previous studies ${ }^{(35,38)}$.

The FTIR spectra of PM and that of the selected SSD16 formula (Figure 6 and 7) showed mostly the characteristic peaks of CCS, that overwhelmed the peaks of EBS, as CCS was mixed at a ratio of 1:15 (EBS:CCS). The only characteristic peak of ketonic carbonyl group ( $\mathrm{C}=\mathrm{O}$ stretch) for EBS was observed in the same position in both figures with low intensity due to dilution of drug with the high amount of CCS. The absence of new peaks in SSD16 spectrum confirmed absence of chemical interaction.

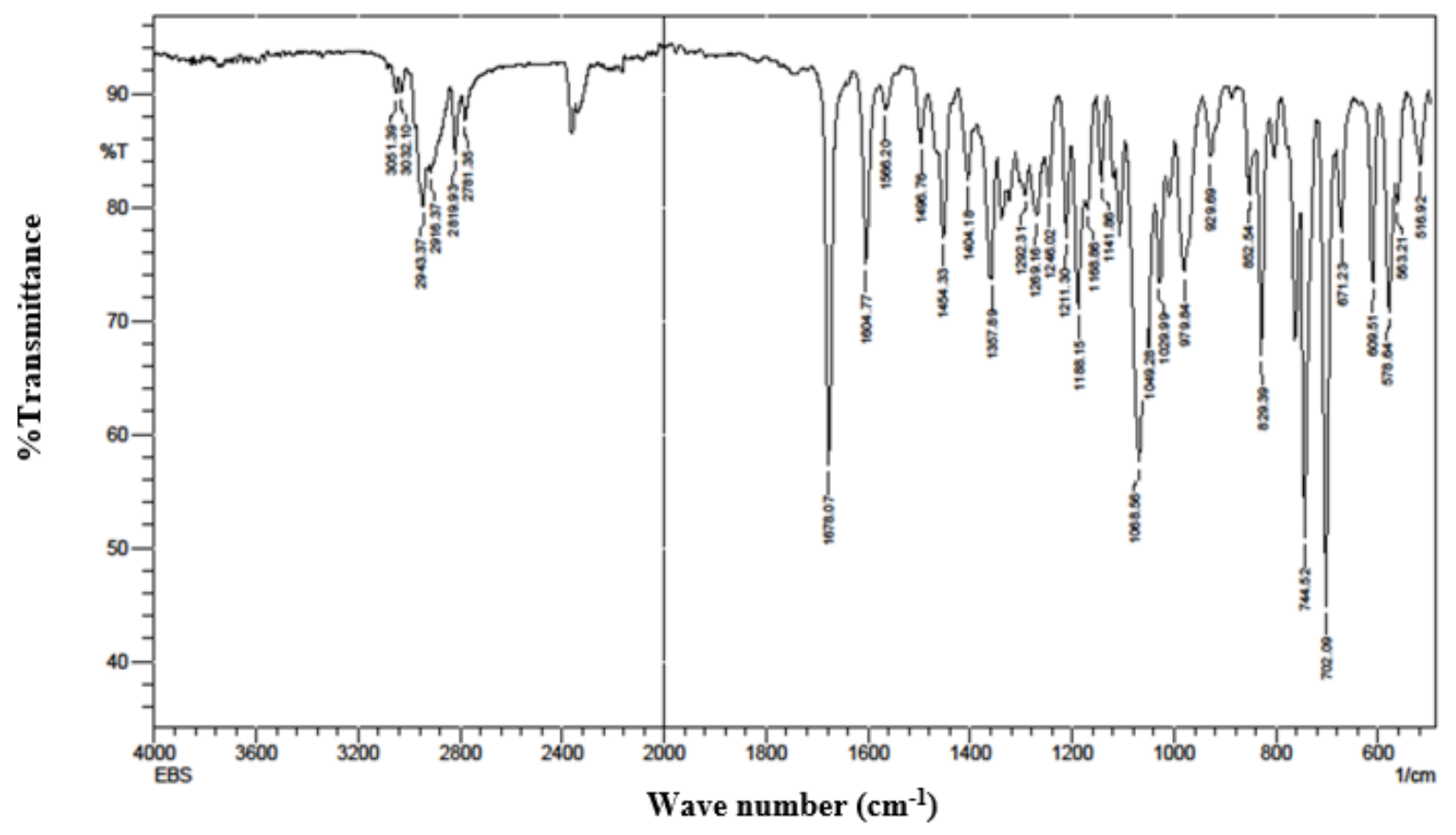

Figure 4 .FTIR spectrum of EBS 


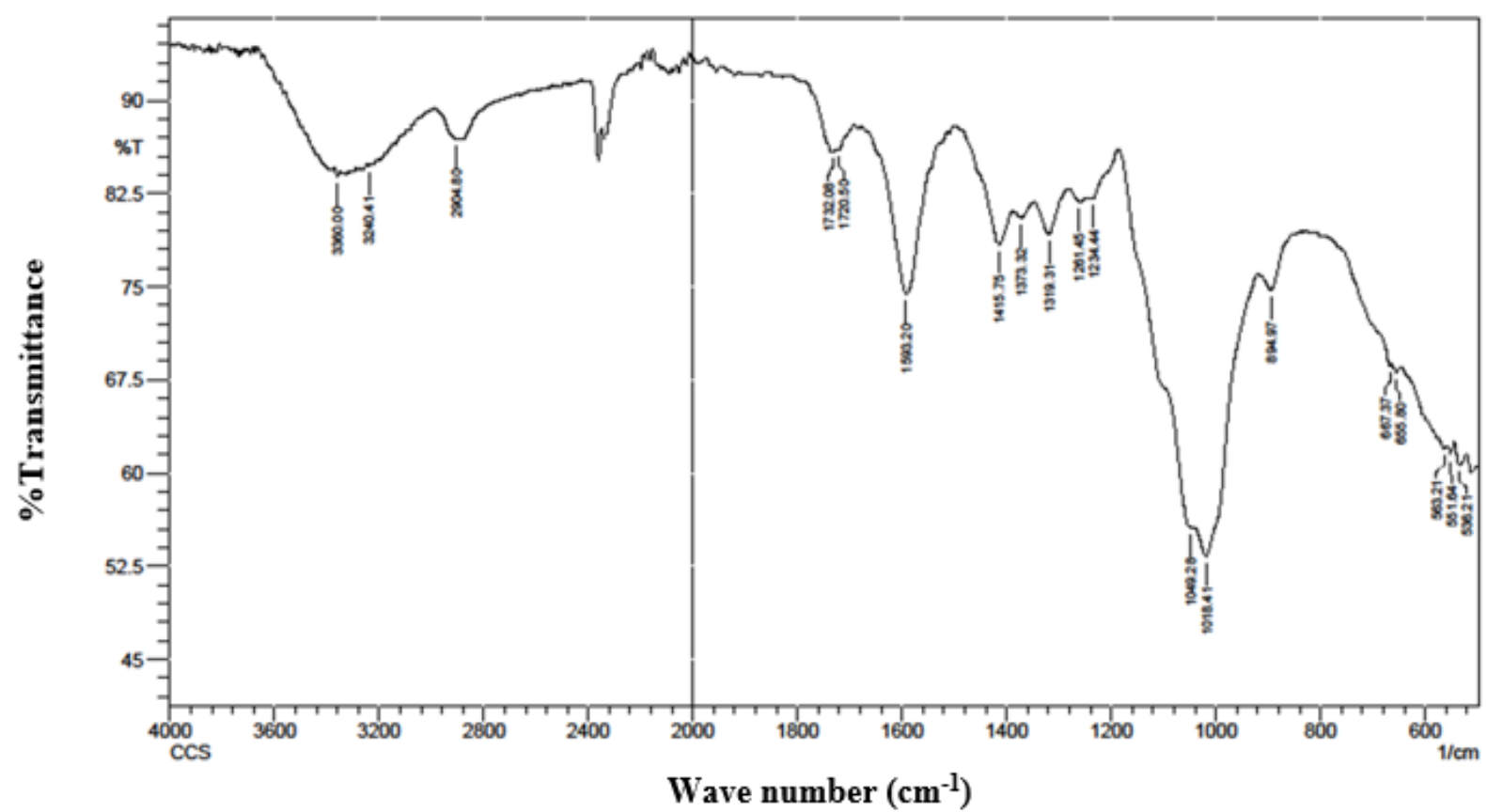

Figure 5. FTIR spectrum of CCS

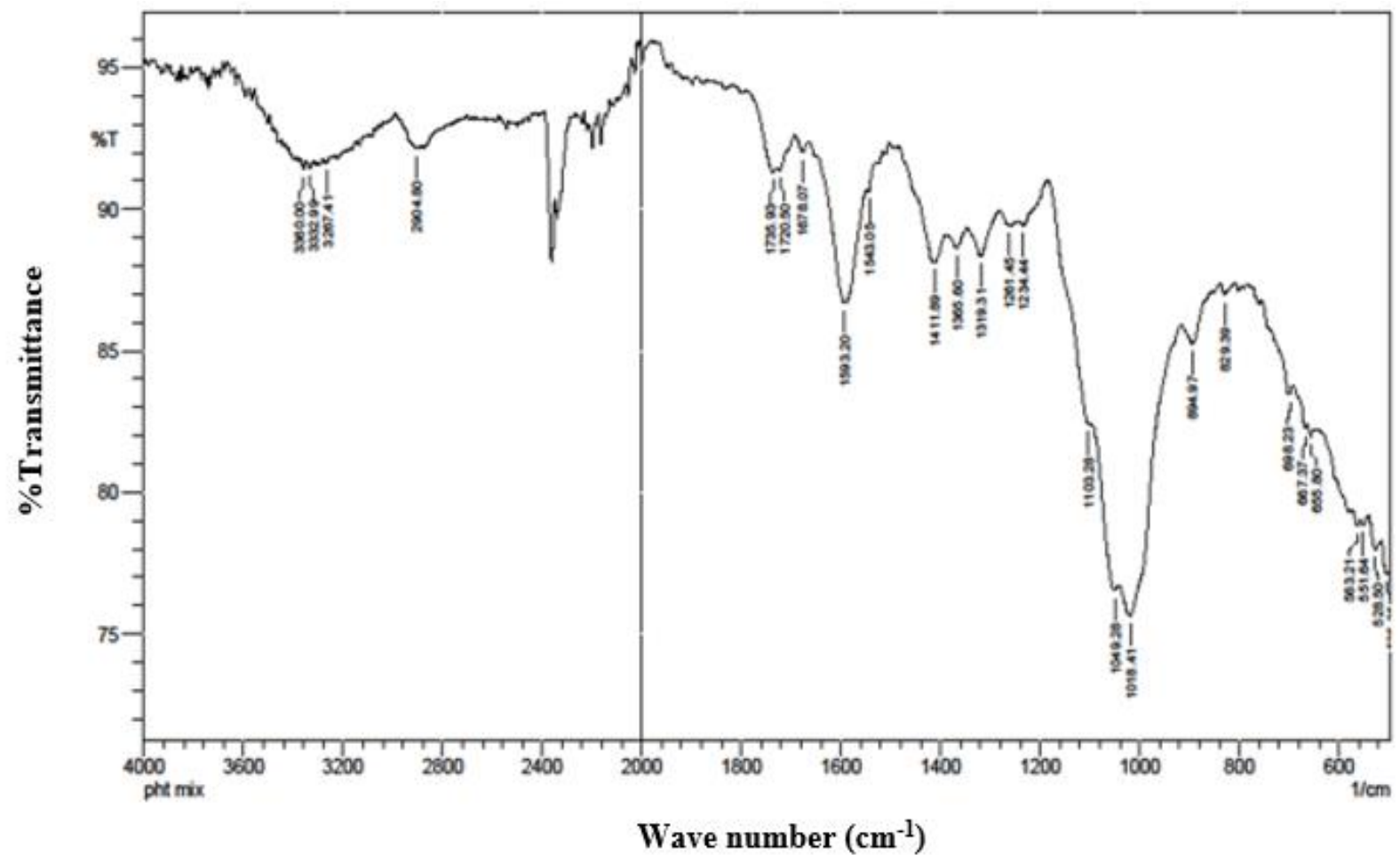

Figure 6. FTIR spectrum of PM 


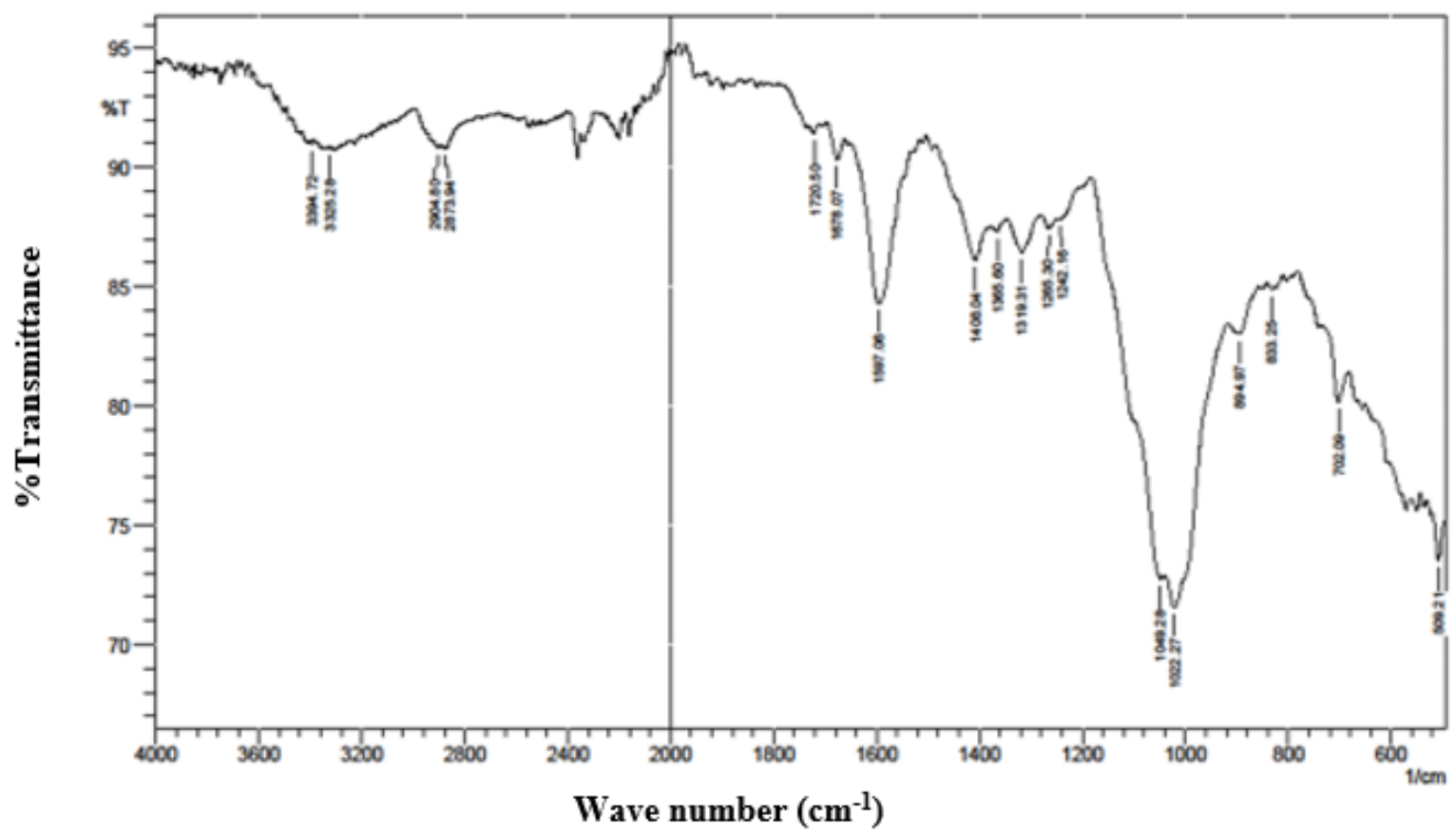

Figure 7. FTIR spectrum of SSD16

\section{Powder X-ray diffraction (PXRD)}

The PXRD patterns of EBS, CCS, PM and SSD16 are shown in figures (8-11), respectively. The diffraction pattern of the pure EBS showed a highly crystalline nature, indicated by numerous intensive peaks at a diffraction angle of $2 \theta\left(5.84^{\circ}\right.$, $\left.11.54^{\circ}, 18.68^{\circ}, 19.06^{\circ}, 19.39^{\circ}\right)$ throughout the scanning range. These values approached the previously reported data ${ }^{(36,39)}$. On the other hand, the CCS diffractogram did not show sharp peaks, but only some peaks with low intensity at $18.41^{\circ}, 22.9^{\circ}$, $43.95^{\circ}, 64.29^{\circ}, 77.38^{\circ}$ related to its amorphous nature ${ }^{(40)}$.
The characteristic peaks identified in the EBS PXRD were not detected neither in PM nor in SSD16 PXRD patterns whereas, peaks corresponding to the CCS were still present in both of them, indicating the predominant effect of the high amount of the carrier in this formula. The broad shape with further decrease in intensity observed in SSD16 PXRD pattern compared to that of PM may be explained by the conversion of the drug to an amorphous form, which contributed to the enhancement of its solubility ${ }^{(41,42)}$.

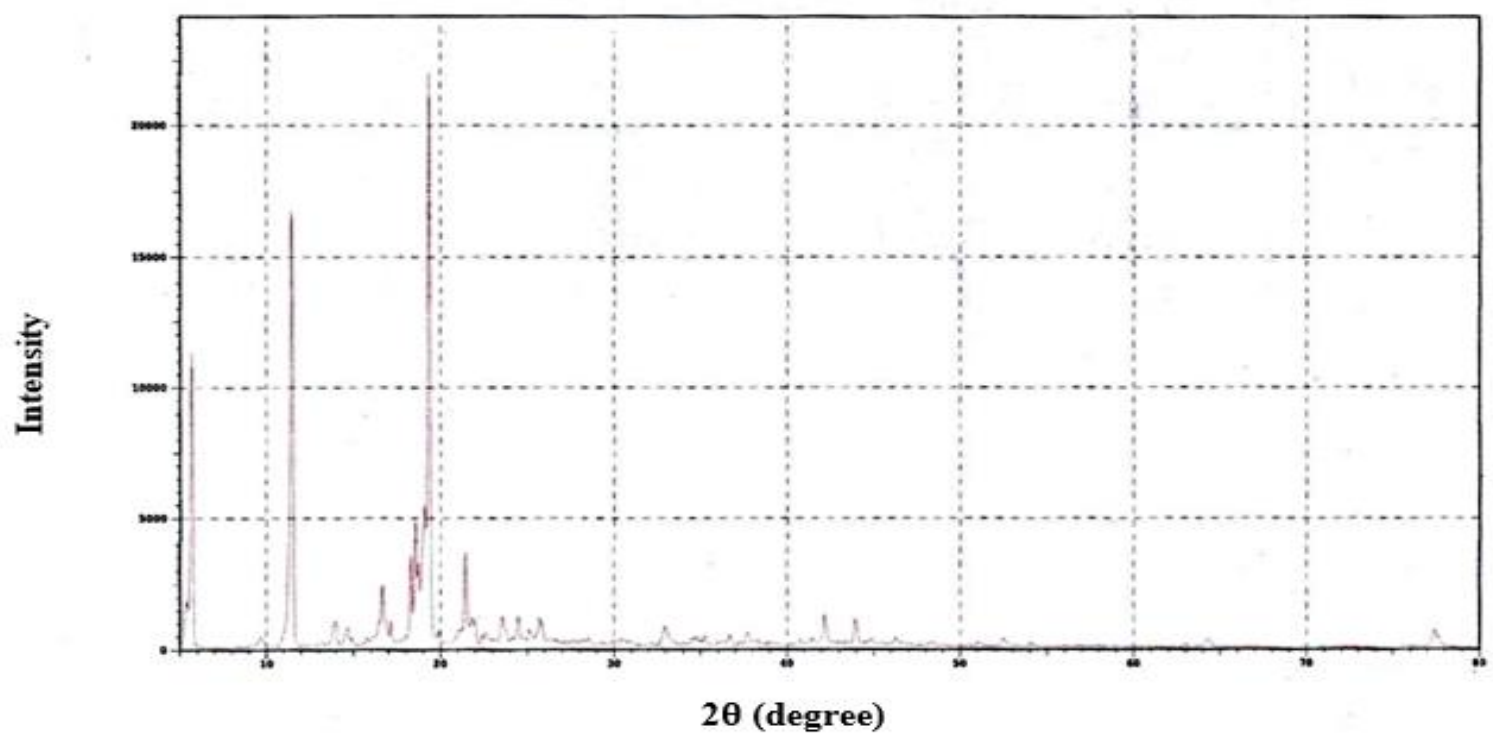

Figure 8. PXRD diffractogram of EBS 


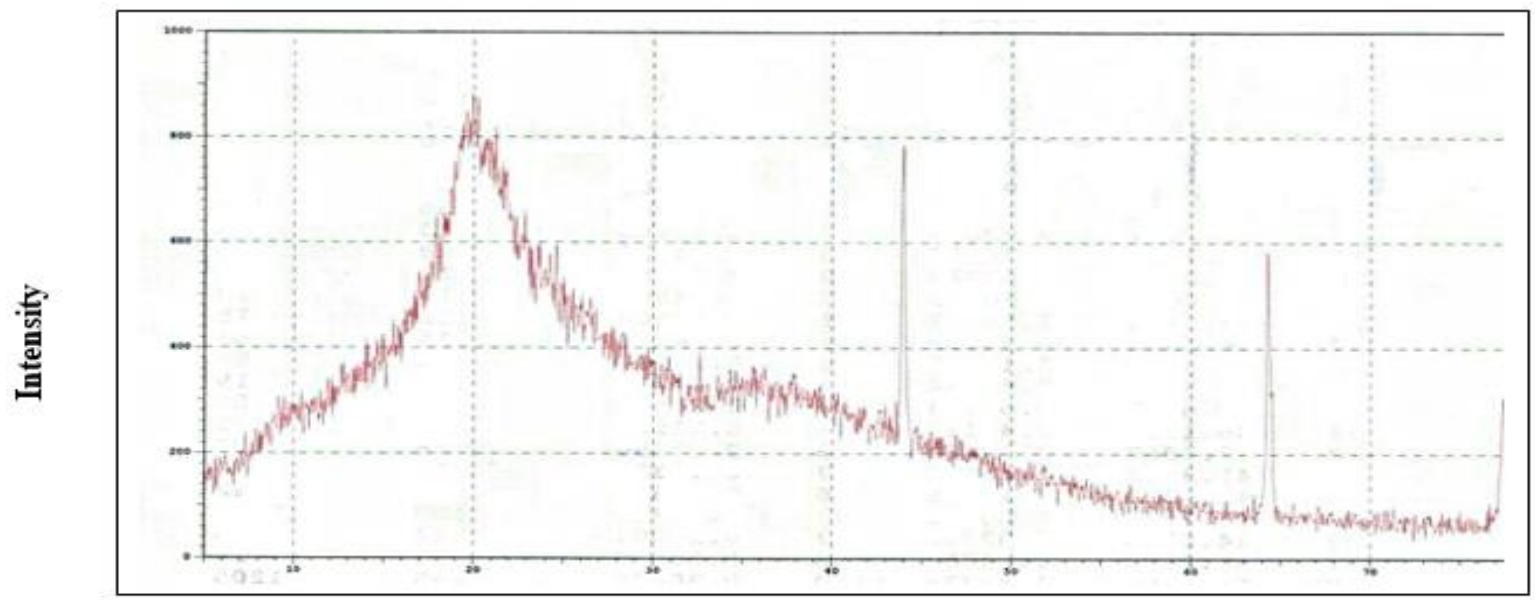

$2 \theta$ (degree)

Figure 9. PXRD diffractogram of CCS

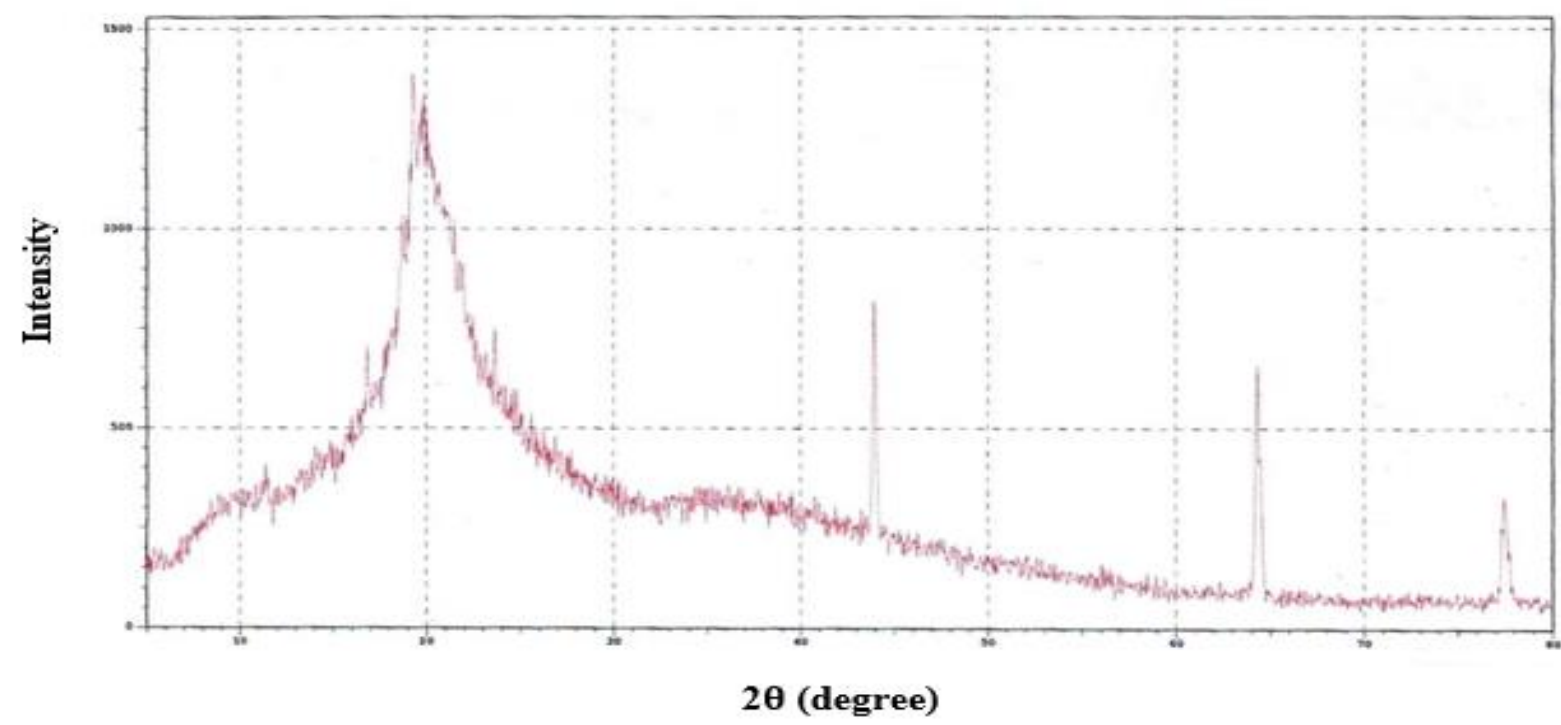

Figure 10. PXRD diffractogram of PM

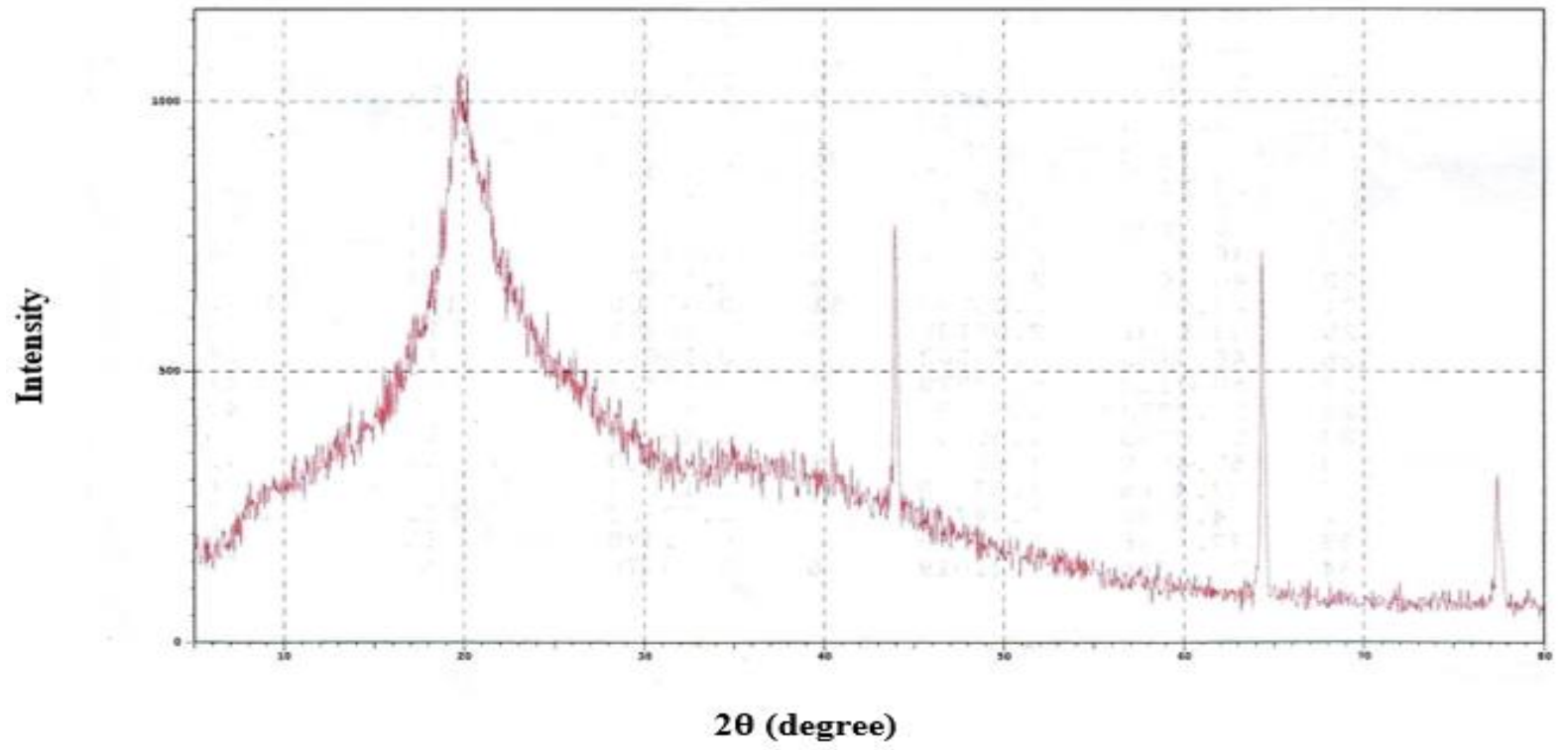

Figure 11. PXRD diffractogram of SSD16 


\section{Conclusion}

An improvement in the solubility and dissolution rate of EBS, a poorly water soluble drug, was successfully obtained by surface solid dispersion technique using CCS as a hydrophilic water insoluble carrier at a ratio of 1:15 EBS:CCS. The enhanced wettability, decrease in particle size, increase the interfacial contact between the drug and the solvent accompanied with decrease crystallinity were the most important factors resulted in improvement of solubility and dissolution.

\section{Acknowledgement}

The authors are grateful to acknowledge the College of Pharmacy -University of Baghdad for providing the necessary facilities to carry out this work. The authors are also thankful to Pioneer Pharmaceutical Company, Iraq, for their generous help for providing gift samples of required materials.

\section{References}

1. Sinko PJ. Solubility and distribution phenomena. In: Martin's physical pharmacy and pharmaceutical sciences. 6th ed. Baltimore: Lippincott Williams and Wilkins; 2011. p182196.

2. Singh G, Kaur L, Gupta G D, Sharma S. Enhancement of the solubility of poorly water soluble drugs through solid dispersion: a comprehensive review. Indian J Pharm Sci. 2017;79(5): 674-687.

3. Saharan VA, Kukkar V, Kataria M, Gera M, Choudhury PK. Dissolution enhancement of drugs. Part I: technologies and effect of carriers. Int J Heal Res. 2009;2(2): 107-124.

4. Shahi SR, Arshiya K, Bhalerao P, Pavan A. A review on formulation aspects of solid dispersions. EJPMR. 2017;4(12): 148-160.

5. Khatry S, Sood N, Arora S. Surface solid dispersion-A review. Int $\mathbf{J}$ Pharm Sci Nanotechnol. 2013;6(1): 1915-1924.

6. Kiran $\mathrm{T}$, Shastri $\mathrm{N}$, Ramakrishna $\mathrm{S}$, Sadanandam M. Surface solid dispersion of glimepiride for enhancement of dissolution rate. Int J Pharm Tech Res. 2009; 1(3): 822-831.

7. Bayer G. Martindale: the complete drug reference. London: Pharmaceutical Press;2015.

8. Kamisetti RR, Gupta VRM. Solubility Enhancement of Ebastine by SelfNanoemulsifying Delivery Strategy: Formulation , Optimization and Characterization. Int J Pharm Sci Nanotech. 2017;10(4): 3779-3787.

9. British Pharmacopoeia. Electronic version, London: TSO; 2016.

10. Abd-El Bary A, Louis D, and Sayed S. Olmesartan medoxomil surface solid dispersion-based orodispersible tablets: formulation and in-vitro characterization. J. Drug Del. Sci. Tech. 2014;24(6): 665-672.
11. Pekamwar SS, Kankudte AD and Kale GK. Formulation and evaluation of solid dispersion of lopinavir by using different techniques. Int. Res. J. Pharm. 2015;6(9): 663-669.

12. Srikanth A, Raju P, Devanna A. Dissolution enhancement of tacrolimus by surface solid dispersion technique. Int. J. Res. Pharm. Sci. 2015;6(2): 178-184.

13. Chaithanya P, Charyulu RN, Sandeep DS. Design and evaluation of ebastine fast dissolving oral films. IJPSR. 2018 ;9(10): 43034308.

14. Das A, Nayak AK, Mohanty B, Panda S. Solubility and dissolution enhancement of etoricoxib by solid dispersion technique using sugar carriers. ISRN Pharmaceutics. 2011: 1-8.

15. Jouyban A. Handbook of solubility data for pharmaceuticals. Boca Raton: CRC Press, Taylor \& Francis Group;2010.p 3.

16. Dadhich T, Kumar M, Pathak K. Capsulated surface solid dispersion of loperamide for targeted delivery. Pharm Chem J. 2016; 3(4): 78-90.

17. Fernandez D, Mendoza N, Solid pharmaceutical composition containing a crystalline derivative of piperidine substituted in the 1,4 position. European Patent Application. 2006. EP 1716848 A1.

18. Watson DG. Pharmaceutical analysis. $3^{\text {rd }}$ ed. London: Elsevier Ltd; 2012.p 115-137.

19. Aboutaleb AE, Abdel-Rahman SI, Ahmed MO, Younis MA. (2016). Improvement of domperidone solubility and dissolution rate by dispersion in various hydrophilic carriers. J App Pharm Sci. 2016; 6(7): 133-139.

20. Lobo MS, Costa P. Modeling and comparison of dissolution profiles. Eur $\mathbf{J}$ Pharm Sci. 2001;13: 123-133.

21. The United State Pharmacopeia (USP) 39, NF34. Convention Inc. Rockville, MD. 2016

22. Maulvi FA, Dalwadi SJ, Thakkar VT, Tejal GS, Gohel MC, Gandhi TR .Improvement of dissolution rate of aceclofenac by solid dispersion technique. Powder Technol.2011;207: 47-54.

23. Ganapuram B, Alle M, Dadigala R, Kotu G, Guttena V. Development, evaluation and characterization of surface solid dispersion for solubility and dispersion enhancement of irbesartan. Journal of Pharmacy Research. 2013;7(6): 472-477.

24. Roa M, Mandage $Y$, Thanki K, Bhise S. Dissolution improvement of simvastatin by surface solid dispersion technology. Dissolut. Technol.2010;17(2): 27-34.

25. Abduljabbar HH, Abd alhammid SN. Enhancement of the solubility and the dissolution rate of tamoxifen citrate solid dispersion using soluplus by solvent 
evaporation technique. Asian J Pharm Clin Res. 2019;12(1): 216-221.

26. Pamudji JS, Wikarsa S, Tampara MH. Improvement of gliclazide's dissolution rate by using surface solid dispersion with avicel $\mathrm{PH}$ 101. Int J Pharm Pharm Sci. 2014;6(11): 461465.

27. Balasubramaniam $\mathrm{J}$, Bee $\mathrm{T}$. The influence of superdisintegrant choice on the rate of drug dissolution. Pharm Technol. 2009;21(9): 1-3.

28. Jain S, Sandhu P, Gurjar M, Malvi R. Solubility enhancement by solvent deposition technique: an overview. Asian J Pharm Clin Res. 2012;5(4), 15-19.

29. Dixit RP, Nagarsenker MS. In vitro and in vivo advantage of celecoxib surface solid dispersion and dosage form development. Indian J Pharm Sci. 2007;69(3): 370-377.

30. Castro SG, Ramirez-Rigo MV, Allemandi DA, Palma SD. New binary solid dispersion of indomethacin and crosscarmellose sodium: physical characterization and in vitro dissolution enhancement. J Excip Food Chem. 2012;3(4): 121-128.

31. Neha S, Sadhna K, Sandeep A. Enhancement of dissolution of telmisartan by surface solid dispersion technique. Journal of Pharmaceutical Research. 2012:11(4): 142-149.

32. Al-Khedairy EB. Effect of additives on the solubility and dissolution of piroxicam from prepared hard gelatin capsule. Iraqi J Pharm Sci 2012;21(1): 117-122.

33. Wierik GP., Bolhuis GK, Zuurman K, Lerk CF. Improvement of dissolution of poorly soluble drugs by solid deposition on a super disintegrant. I: Physical mixtures. Acta pharmaceutica Nordica. 1992; 4(4): 239-244.

34. Jain S, Sandhu P, Gurjar M, Malvi R. Solubility enhancement by solvent deposition technique: an overview. Asian J Pharm Clin Res. 2012;5(4), 15-19.

35. Yadav LDS. Infrared (IR) Spectroscopy. In: Organic spectroscopy. 1st ed. Berlin: Springer Science \& Business Media.2005. P 52-106.

36. Harmalkar D, Godinho S, Bhide PJ, Kumar L, Shirodkar RK. New formulation technique for solubility and dissolution rate enhancement of poorly soluble drugs. Pharmaceutical Chemistry Journal. 2019;53(8): 720-729.

37. Khom TC, Yadav H K, Raizaday A, Manne N, Kumar HS, Kumar SN. Development of mucoadhesive nanoparticulate system of ebastine for nasal drug delivery. Trop J Pharm Res. 2014;13(7): 1013-1019.

38. Rani KC, Parfati N, Yosanti L, Ayu IG. Formulation of orodispersible atenolol- $\beta$ cyclodextrin tablets with co-processed crospovidone-croscarmellose sodium and poloxamer 188. Pharmaciana. 2019;9(2): 283298.

39. Hareeja MM, Al-Khedairy EB. Formulation and evaluation of spherical crystal agglomerates of ebastine for preparation of directly compressible oral dispersible tablets. MSc. thesis College of Pharmacy. University of Baghdad.2018.

40. Chowdary KPR, Rao SS. Investigation of dissolution enhancement of itraconazole by solid dispersion in superdisintegrants. Drug Dev Ind Pharm. 2000;26(11): 1207-1211.

41. Mahajan HS, Girnar GA, Nerkar P. Dissolution and bioavailability enhancement of gliclazide by surface solid dispersion using spray drying technique. Indian J. Novel Drug Deliv. 2012;4(2): 115-124.

42. Charumanee S, Okonoki S, Sirithunyalug J. Improvement of the dissolution rate of piroxicam by surface solid dispersion. CMU J. 2004; 3(2): 77-84. 